\title{
Mixed and Fluid Film Lubrication Characteristics of Worn Journal Bearings
}

\author{
Toshiharu Kazama and Yukihito Narita \\ College of Manufacturing and Design Technology, Muroran Institute of Technology, 27-1, Mizumoto-cho, \\ Hokkaido, Muroran 050-8585, Japan \\ Correspondence should be addressed to Toshiharu Kazama, kazama@mmm.muroran-it.ac.jp
}

Received 30 June 2011; Accepted 8 December 2011

Academic Editor: Gun Hee Jang

Copyright ( $\odot 2012$ T. Kazama and Y. Narita. This is an open access article distributed under the Creative Commons Attribution License, which permits unrestricted use, distribution, and reproduction in any medium, provided the original work is properly cited.

\begin{abstract}
The mixed and fluid film lubrication characteristics of plain journal bearings with shape changed by wear are numerically examined. A mixed lubrication model that employs both of the asperity-contact mechanism proposed by Greenwood and Williamson and the average flow model proposed by Patir and Cheng includes the effects of adsorbed film and elastic deformation is applied. Considering roughness interaction, the effects of the dent depth and operating conditions on the loci of the journal center, the asperity-contact and hydrodynamic fluid pressures, friction, and leakage are discussed. The following conclusions are drawn. In the mixed lubrication regime, the dent of the bearing noticeably influences the contact and fluid pressures. For smaller dents, the contact pressure and frictional coefficient reduce. In mixed and fluid film lubrication regimes, the pressure and coefficient increase for larger dents. Furthermore, as the dent increases and the Sommerfeld number decreases, the flow rate continuously increases.
\end{abstract}

\section{Introduction}

Hydrodynamic journal bearings are widely used as main shaft bearings of various machinery and equipment such as gas turbines, turbo generators, pumps, and machine tools [1-4]. Punctual and appropriate maintenance of the bearings that ensures they are lubricated by a fluid film enables them to operate for a long time.

However, the sliding surfaces partially contact at the startup, shutdown, and under low-speed conditions, namely, the bearings are imposed to operate in the mixed lubrication regime. The materials of the sliding parts of the bearing bush are often composed of relatively soft metals such as white metal and copper-aluminum alloys. Thus, when the bearings are operated in the mixed lubrication regime for a specific period, the sliding surfaces are plastically deformed and worn [5], forming dents and resulting in clearance shape changes from its dimensions at design. This shape change affects the bearing performance.

The static and dynamic characteristics of worn journal bearings have been studied by Hashimoto and Wada [6, 7], Kumar and Mishra[8, 9], and Tanaka and Suzuki $[10,11]$.
In parallel, their thermohydrodynamic characteristics have also been studied by Fillon and Bouyer [12]. The mixed lubrication characteristics of journal bearings have been studied by many researchers, for example, S. A. Mckee and T. R. Mckee [13], Burwell et al. [14], Kreisle [15], Kazama and Fujiwara [16], Nonogaki and Nakahara [17], and Wang et al. [18-20]. However, a few theoretical studies of dented journal bearings that include interactions between roughness asperities and surface contacts have been published.

This study numerically analyzes plain hydrodynamic journal bearings with a wear dent model in the fluid film and mixed lubrication regimes. Including roughness interaction, the effects of shape changed by wear on friction and leakage as well as contact pressure and fluid pressure are examined. Furthermore, the bearing characteristics are discussed under the isothermal and steady-state condition.

\section{Theory}

2.1. Theoretical Model and Coordinates. Figure 1 shows the coordinates of the hydrodynamic journal bearing model with a wear dent. The interference and contact of the mating 


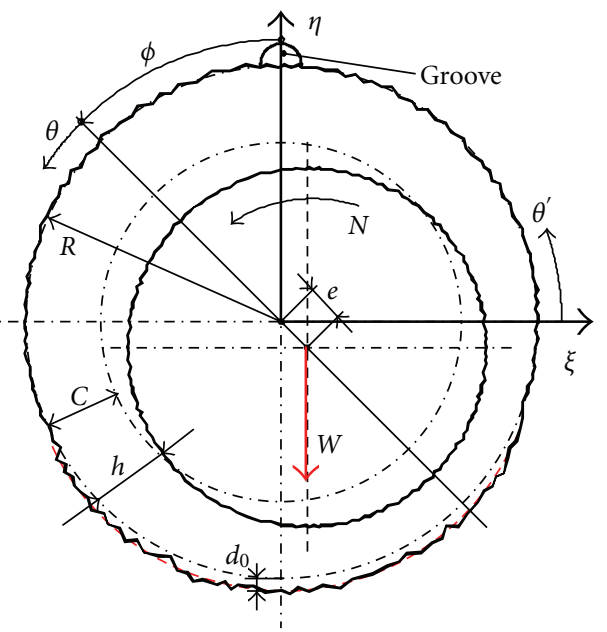

FIGURE 1: Schematic and coordinates of a plain hydrodynamic journal bearing with a wear dent.

surface roughness are considered, whereas misalignment of the journal, the effects of heat generation, and the condition of dynamic loading are neglected. Laminar flow of the lubricant in the bearing clearance is assumed.

A mixed lubrication model [21] that employs the asperity-contact mechanism proposed by Greenwood and Williamson (hereafter, the GW model) [22] and the average flow model proposed by Patir and Cheng (hereafter, the PC model) $[23,24]$ is used for this analysis. The details of this lubrication model are described in $[25,26]$.

2.2. Nondimensional Basic Equations. The load-carrying capacity of asperity contact is estimated from the capacities in elastic and plastic contact. The asperity-contact pressures $\bar{p}_{a e}$ and $\bar{p}_{a p}$ averaged over a small apparent area is given by [22]

$$
\begin{gathered}
\bar{p}_{a e}=\frac{2}{3} \bar{E}^{\prime} \eta \beta^{\prime} \sigma^{*}\left(\frac{\sigma^{*}}{\beta^{\prime}}\right)^{1 / 2}\left[F_{3 / 2}\left(d_{e}^{*}\right)-F_{3 / 2}\left(d_{e}^{*}+w_{p}^{*}\right)\right], \\
\bar{p}_{a p}=\pi \bar{H}_{a} \eta \beta^{\prime} \sigma^{*} F_{1}\left(d_{e}^{*}+w_{p}^{*}\right),
\end{gathered}
$$

where $d_{e}^{*}$ is the separation, $\bar{E}^{\prime}$ is the equivalent modulus of elasticity $=E^{\prime} /\left[6 \mu \omega(R / C)^{2}\right], \bar{H}_{a}$ is the hardness of the softer material $=H_{a} /\left[6 \mu \omega(R / C)^{2}\right], w_{p}^{*}=\left(\beta^{\prime} / \sigma^{*}\right)\left(2 H_{a} / E^{\prime}\right)^{2}$, $\beta^{\prime}$ is the mean radius of asperities, $\eta$ is the density of asperity, and $\sigma^{*}$ is the standard deviation of the asperity summit height $=0.7 \sigma$. The relationship $d_{e}^{*}=h_{s}\left(h_{s} \geq 1.8\right)$ and $d_{e}^{*}=1.5 h_{s}-0.9\left(h_{s}<1.8\right)$ holds for these mean planes [27]. The subscripts $e$ and $p$ represent the elastic and plastic deformation of asperities, respectively. Moreover, the function $F_{m}$ is expressed as follows:

$$
F_{m}\left(h_{s}\right)=\int_{h_{s}}^{\infty}\left(s-h_{s}\right)^{m} \psi(s) d s,
$$

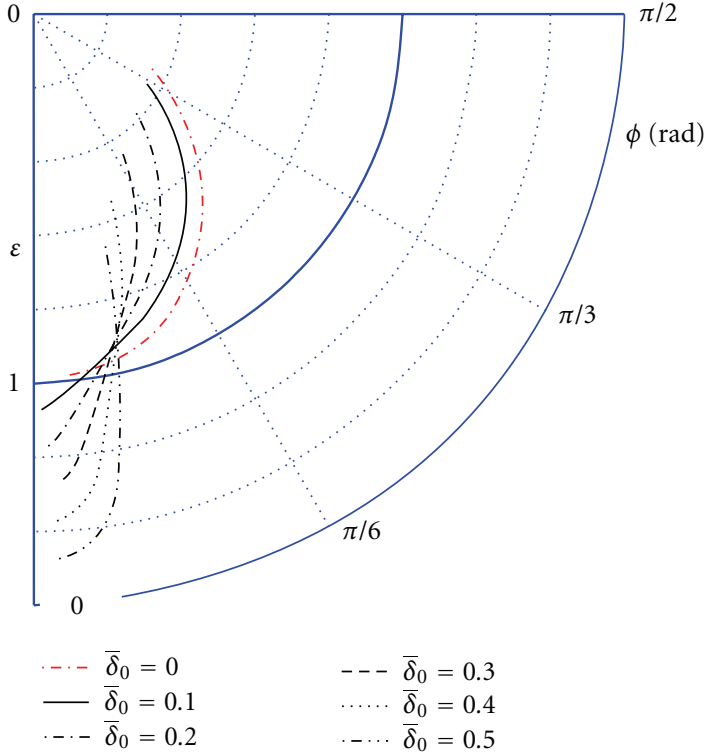

Figure 2: Loci of journal center.

where $\psi(s)$ is the standard probability density function $=$ $(2 \pi)^{-1 / 2} \exp \left(-s^{2} / 2\right)$. The standard plane of rough surfaces is either the summit mean plane or the surface mean plane, where the former is used in the GW model and the latter in the PC model [23, 24].

Following the PC model, the average Reynolds equation is described as follows:

$$
\frac{\partial}{\partial \theta}\left(\phi_{\theta} \overline{h^{3}} \frac{\partial \bar{p}_{f}}{\partial \theta}\right)+\left(\frac{R}{L}\right)^{2} \frac{\partial}{\partial \bar{y}}\left(\phi_{y} \overline{h^{3}} \frac{\partial \bar{p}_{f}}{\partial \bar{y}}\right)=\frac{\partial \bar{h}_{T}^{*}}{\partial \theta}+\frac{\sigma}{C} \frac{\partial \phi_{s}}{\partial \theta},
$$

where $\phi_{\theta}$ and $\phi_{y}$ are the pressure flow factors along the $\theta$ and $y$ axes, respectively, and $\phi_{s}$ is the shear flow factor. The pressure boundary conditions are as follows: $\bar{p}_{f}=\bar{p}_{e}$ (= atmospheric pressure) at the side-end of the bearing and $\bar{p}_{f}=\bar{p}_{g}$ (= fluid pressure in the groove) at the edge of the supply ports.

The equilibrium of load $\bar{W}$ due to contacting asperity and fluid can be computed from the following integrals:

$$
\begin{gathered}
\int_{0}^{2 \pi} \int_{0}^{1}\left(\bar{p}_{a}+\bar{p}_{f}\right) \cos \theta d \bar{y} d \theta=0, \\
\int_{0}^{2 \pi} \int_{0}^{1}\left(\bar{p}_{a}+\bar{p}_{f}\right) \sin \theta d \bar{y} d \theta+\frac{R}{L} \bar{W}=0 .
\end{gathered}
$$

The side leakage flow rate $\bar{Q}_{s}$ is given by

$$
\bar{Q}_{s}=\frac{1}{2}\left(\frac{R}{L}\right)^{2} \int_{0}^{2 \pi} \phi_{y} \overline{h^{3}}\left(\left.\frac{\partial \bar{p}_{f}}{\partial \bar{y}}\right|_{\bar{y}=-1 / 2}-\left.\frac{\partial \bar{p}_{f}}{\partial \bar{y}}\right|_{\bar{y}=1 / 2}\right) d \theta .
$$




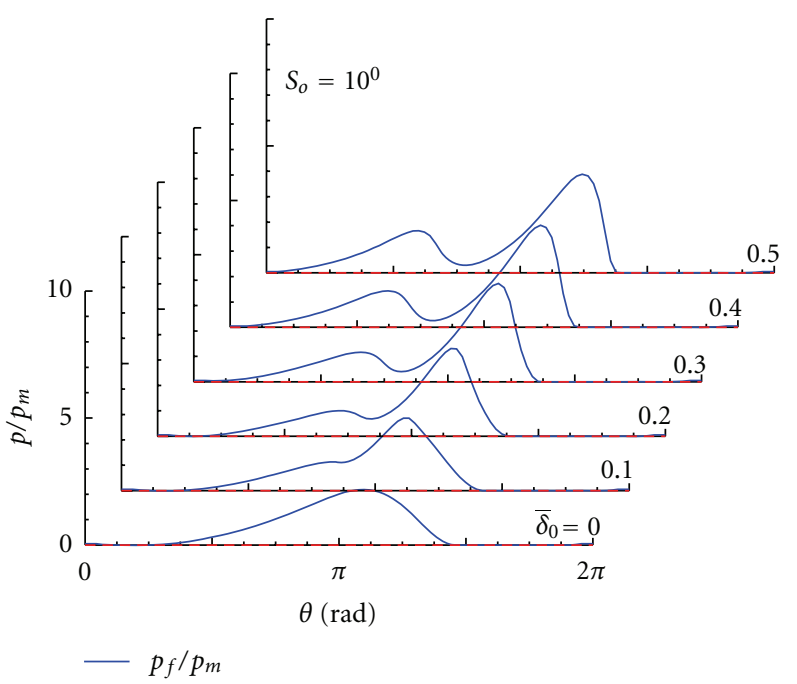

(a)

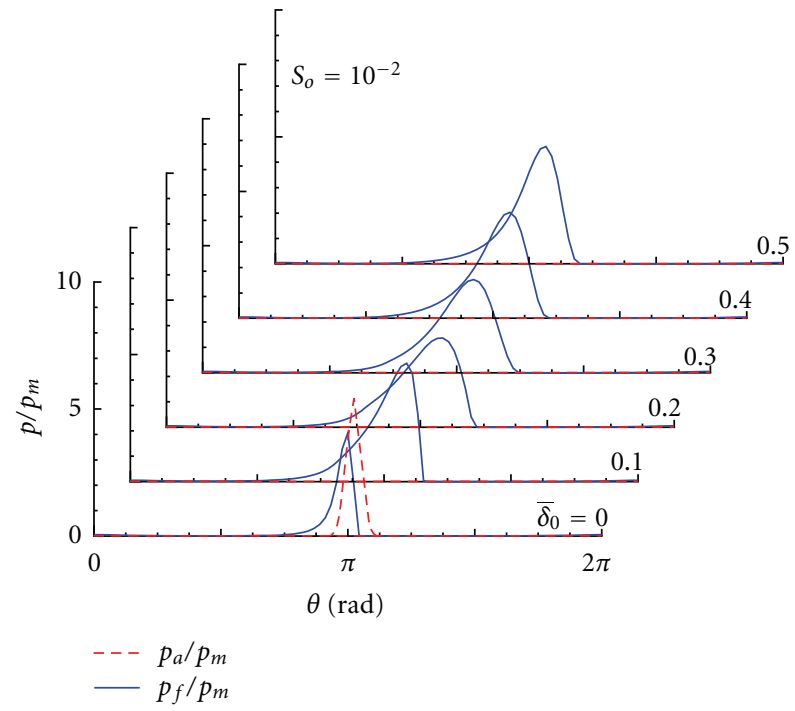

(c)

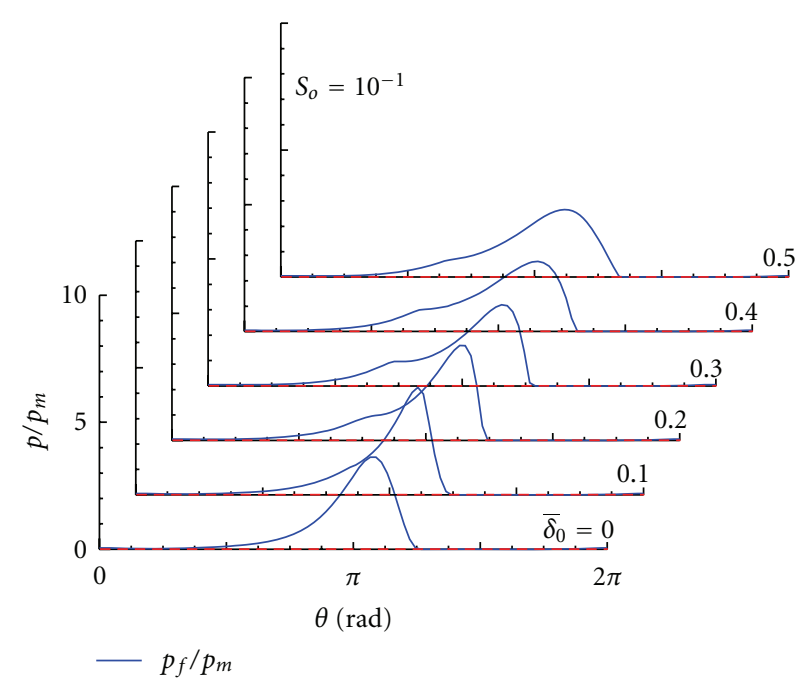

(b)

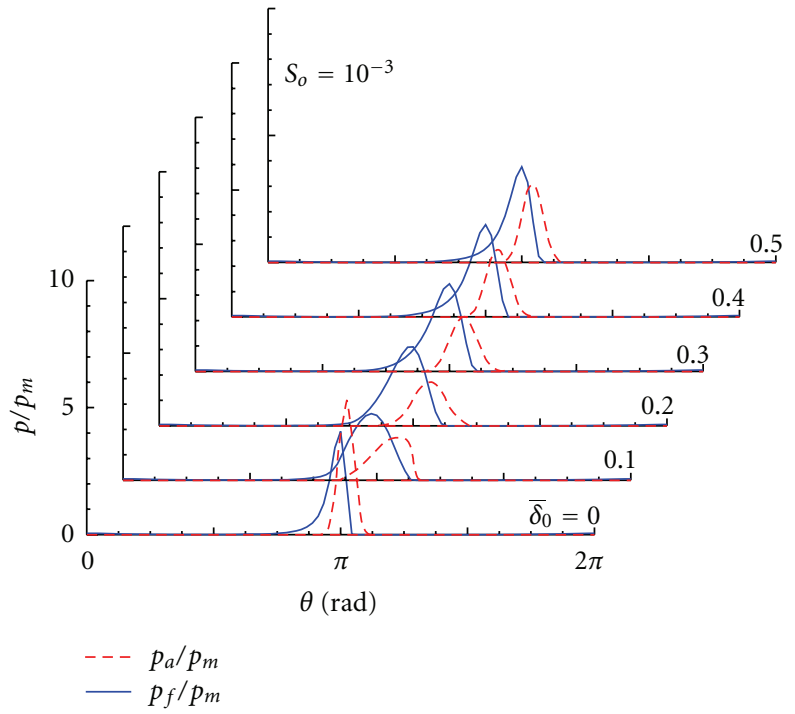

(d)

FIgURe 3: (a) Distributions of fluid pressures $\bar{p}_{f}\left(S_{o}=10^{0}\right)$ (b) distributions of fluid pressures $\bar{p}_{f}\left(S_{o}=10^{-1}\right)$; (c) distributions of asperitycontact pressures $\bar{p}_{a}$ and fluid pressures $\bar{p}_{f}\left(S_{o}=10^{-2}\right)$; (d) distributions of asperity-contact pressure $\bar{p}_{a}$ and fluid pressure $\bar{p}_{f}\left(S_{o}=10^{-3}\right)$.

In addition, the friction $\bar{F}_{a}$ due to the asperities in contact and the friction $\bar{F}_{f}$ due to fluid acting on the sliding surface are formulated below [25]:

$$
\begin{gathered}
\bar{F}_{a}=\frac{L}{R} \iint_{\bar{A}_{0}} \xi \bar{\tau}_{p}\left(\frac{\bar{\tau}_{e}}{\bar{\tau}_{p}} d \bar{A}_{e}+d \bar{A}_{p}\right)+(1-\xi) \bar{\tau}_{a d} d \bar{A}_{r}, \\
\bar{F}_{f}=\frac{C L}{6 R^{2}} \int_{0}^{2 \pi} \int_{0}^{1} \frac{1}{\bar{h}}\left\{\left[\phi_{f}+\left(1-2 \frac{\sigma_{1}^{2}}{\sigma^{2}}\right) \phi_{f s}\right]\right. \\
\left.-3 \phi_{f p} \bar{h} \frac{\partial \bar{p}_{f}}{\partial \theta}\right\} d \bar{y} d \theta,
\end{gathered}
$$

where $\bar{A}_{0}\left(=A_{0} / L R\right)$ is the land area, $d \bar{A}_{r} \quad\left(=d \bar{A}_{e}+\right.$ $\left.d \bar{A}_{p}\right)$ is the real contacting area, $d \bar{A}$ is the apparent area, $W^{\prime}\left(=1 /\left(E^{\prime} \beta^{2}\right) \Delta W_{a} /\left[\eta F_{0}\left(d_{e}^{*}\right) \Delta A_{0}\right]\right)$ is the load parameter, $\bar{\tau}\left(=\tau /\left[6 \mu \omega(R / C)^{2}\right]\right)$ is the shearing strength, $\bar{\tau}_{a d}$ is the shearing strength of the adsorbed film. $\phi_{f}, \phi_{f p}$, and $\phi_{f s}$ are the factors after the PC model $[23,24]$. The parameter $\xi\left(=\phi^{\prime} \exp \left[\left(h_{a d} / a_{r}\right)^{m} /\left(\Delta A_{r} / \Delta A_{0}\right)\right]\right)$ is given by the area ratio of solid-contact asperities [25], where $a_{r}$ (= $\left.\left[\beta^{\prime} \sigma^{*} F_{1}\left(d_{e}^{*}\right) / F_{0}\left(d_{e}^{*}\right)\right]^{1 / 2}\right)$ is the mean radius of the asperity contact, $h_{a d}$ is the elastohydrodynamic (EHL) film thickness of the point contact, and $\Delta A_{r} / \Delta A_{0}\left(=\pi\left(\eta \beta^{\prime} \sigma^{*}\right) F_{1}\left(d_{e}^{*}\right)\right)$ is the real contact area ratio under dry friction.

Finally, the friction coefficient $f$ is defined by

$$
f=\frac{\bar{F}_{a}+\bar{F}_{f}}{\bar{W}} .
$$

The clearance $\bar{h}$ of the worn bearing is given by

$$
\bar{h}=1+\varepsilon \sin (\theta-\phi)+\bar{\delta},
$$


where $\bar{\delta}$ represents the wear dent defined as $\bar{\delta}=\bar{\delta}_{0}-1-$ $\cos \left(\theta^{\prime}-\pi / 2\right)$ in $\theta_{s} \leq \theta^{\prime} \leq \theta_{e}$ and $\bar{\delta}_{0}$ is the maximum of wear depth [5].

2.3. Calculation Procedure and Parameters Used. The Reynolds equations are discretized by the finite difference method, and the solutions are obtained by an iterative scheme [16]. The operating conditions are specified by the following parameters: clearance ratio $C / R=0.001$, equivalent elastic modulus $E^{\prime}=83.6 \mathrm{GPa}$, hardness of softer materials $H_{a}=250 \mathrm{MPa}$, bearing-width ratio $L /(2 R)=0.5$, groove width $L_{g} / L=0.8$, lubricant supply pressure $p_{g}=0.1 \mathrm{MPa}$, bearing radius $R=50 \mathrm{~mm}$, bearing load $W=10 \mathrm{kN}$, equivalent radius of the asperity summit $\beta^{\prime}=0.05 \mathrm{~mm}$, $\eta \beta^{\prime} \sigma^{*}=0.05\left(\eta^{\prime}\right.$ : asperity density, $\sigma^{*}$ : standard deviation of the asperity summit height), viscosity $\mu=27.2 \mathrm{mPa} \cdot \mathrm{s}$, circumferential extent angle of groove $\theta_{g}=\pi / 9 \mathrm{rad}$, fluid density $\rho=850 \mathrm{~kg} / \mathrm{m}^{3}$, equivalent surface roughness $\sigma=$ $1 \mu \mathrm{m}$, shear strength of the adsorbed film $\tau_{a d}=15 \mathrm{MPa}$, and shear strength at the plastic contact $\tau_{p}=70 \mathrm{MPa}$. The roughness is assumed to be isotropic, so that the roughness parameter $\gamma$ in the PC model is unity.

\section{Results and Discussion}

Figure 2 shows the loci of the journal with respect to the wear dent $\bar{\delta}$. When the bearing bush is not worn, that is, the maximum wear depth $\bar{\delta}_{o}=0$, the locus is formed as a half circle. As $\bar{\delta}_{o}$ increases, the loci move in the direction of $\phi=$ 0 , that is, vertically. The eccentricity ratio $\varepsilon$ becomes greater than unity because the bush is worn $\left(\bar{\delta}_{0}>0\right)$ and the local clearance is larger than the radial clearance $C$.

Figures 3(a)-3(d) illustrate the fluid pressure $\bar{p}_{f}$ and the asperity-contact pressure $\bar{p}_{a}$ under the operating conditions of $S_{o}=10^{0}-10^{-3}$. Under the conditions of $S_{o}=10^{0}$ and $10^{-1}$, the asperity-contact pressure $\bar{p}_{a}$ remains zero for the entire circumference of the bearing clearance, which corresponds to fluid film lubrication. Under the conditions of $S_{o}=10^{-2}$ and $10^{-3}, \bar{p}_{a}$ is partially positive, which corresponds to mixed lubrication.

In fluid film lubrication (Figures 3(a) and 3(b)), two peaks of $\bar{p}_{f}$ or a peak and a hump seemingly appear for larger $\bar{\delta}_{o}$. This is because two wedge films form in the bearing clearance owing to the wear dent. On the other hand, in mixed lubrication (Figures 3(c) and 3(d)), the contact pressure $\bar{p}_{a}$ peaks at around $\theta=\pi$ rad and the fluid pressure $\bar{p}_{f}$ peaks somewhat upstream at the circumferential location $\theta$ of the $\bar{p}_{a}$ peak. This is because of the surface contact at the minimum clearance and an effective wedge film located just before the minimum clearance. When $\bar{\delta}_{o}=0$, the peaks of $\bar{p}_{a}$ and $\bar{p}_{f}$ are sharp. As $\bar{\delta}_{o}$ slightly increases, the peaks become smooth, and as $\bar{\delta}_{o}$ increases further, both $\bar{p}_{a}$ and $\bar{p}_{f}$ increase.

Figures 4 and 5 depict the effects of the wear dent $\bar{\delta}_{0}$ on the friction coefficient $f R / C$ and the side leakage flow rate $\bar{Q}_{s}$, respectively. In the mixed lubrication regime, the coefficient $f R / C$ is largest for $\bar{\delta}_{0}=0$ and smallest for $\bar{\delta}_{0}=0.1$; for $\bar{\delta}_{0}>$ 0 , as $\bar{\delta}_{0}$ increases, $f R / C$ increases. In the fluid film lubrication

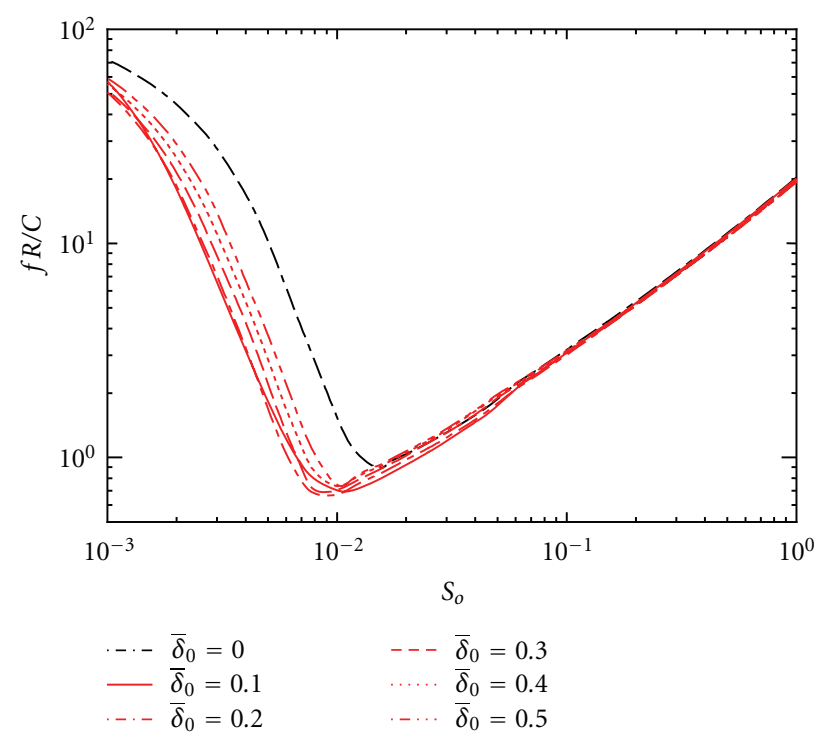

Figure 4: Effect of dent $\bar{\delta}_{o}$ on frictional coefficient $f R / C$.

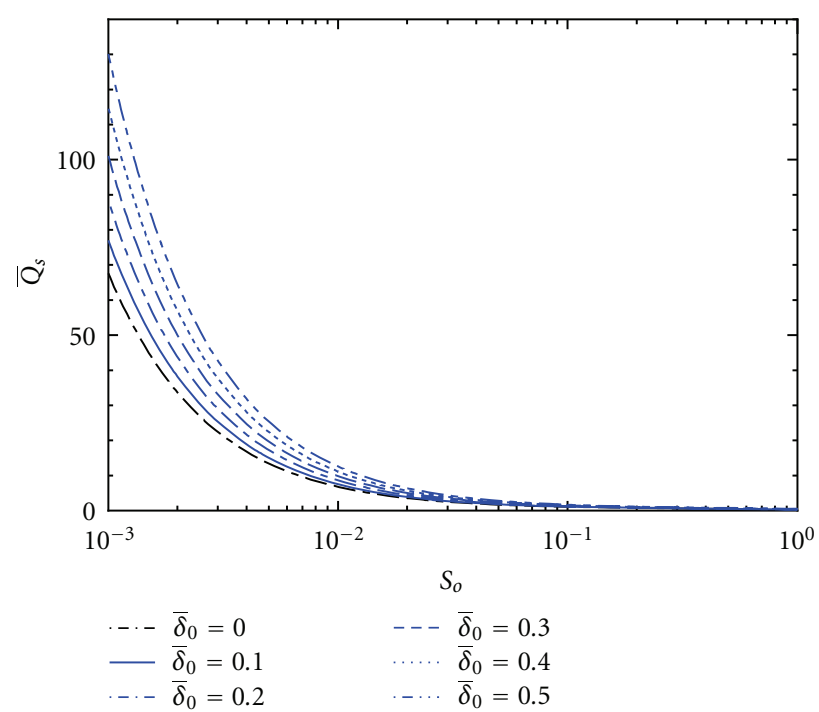

Figure 5: Effect of dent $\bar{\delta}_{o}$ on side leakage flow rate $\bar{Q}_{s}$.

regime, the effects of dent on $f R / C$ are relatively low. In the mixed lubrication regime, the leakage $\bar{Q}_{s}$ increases almost linearly as $\bar{\delta}_{0}$ increases and increases continuously as the Sommerfeld number $S_{o}$ decreases.

Figures 6 and 7 show the maximum fluid pressure $\bar{p}_{f \max }$ and the maximum asperity-contact pressure $\bar{p}_{a \max }$ in terms of the Sommerfeld number $S_{o}$, respectively. The maximum pressure $\bar{p}_{a \max }$ of the asperity contact increases as $S_{o}$ decreases below $S_{o}=10^{-2}$. It is largest at $\bar{\delta}_{0}=0$ and smallest at $\bar{\delta}_{0}=0.1$ but increases as $\bar{\delta}_{0}$ increases. In contrast, the maximum pressure $\bar{p}_{f \max }$ of the fluid pressure varies over $S_{o}=10^{0}-10^{-3}$, where it maximizes around $S_{o}=2$ to $5 \times 10^{-3}$ and minimizes in $S_{o}=10^{-2}-10^{-1}$, except for the case of $\bar{\delta}_{0}$ $=0.1$. In particular, $\bar{p}_{f \max }$ is largest in the mixed lubrication 


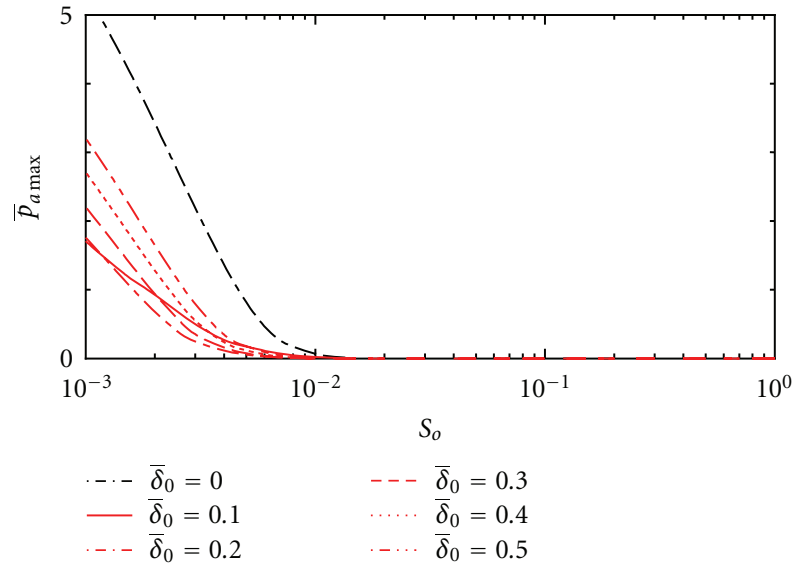

Figure 6: Effect of dent $\bar{\delta}_{o}$ on maximum asperity-contact pressure $\bar{p}_{\text {amax }}$.

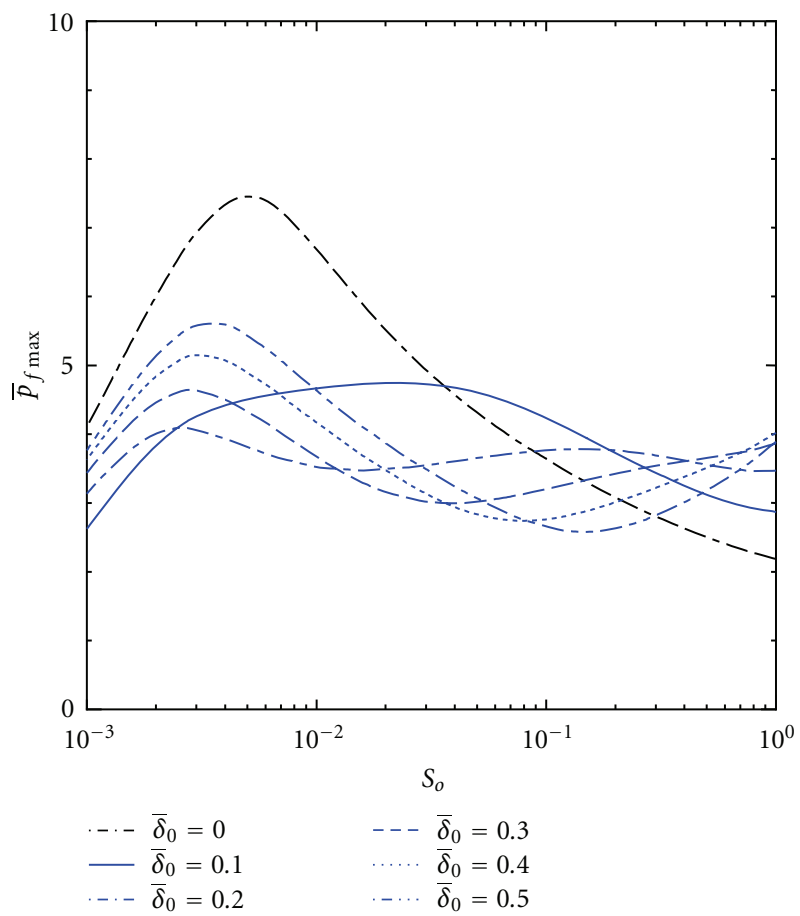

Figure 7: Effect of dent $\bar{\delta}_{o}$ on maximum fluid pressure $\bar{p}_{f \max }$.

regime for bearings with no dents and large wear dents, but it is largest in the fluid film lubrication regime for bearings with slight wear dents. Therefore, a slightly worn bearing bush $\left(\bar{\delta}_{0}=0.1\right)$ enables reducing the maxima of the fluid pressure $\bar{p}_{f \text { max }}$ and the asperity-contact pressure $\bar{p}_{\text {amax }}$.

Figure 8 illustrates the effect of the bearing-width ratio $L / D(D=2 R)$ on the bearing performance. For bearings with and without dents, as the ratio $L /(2 R)$ decreases, the friction coefficient $f R / C$ and the side leakage $\bar{Q}_{s}$ increase over the entire range of $S_{o}=10^{-3}-10^{0}(\bar{\delta}=0.5)$, where there is larger change in the coefficient $f R / C$ in the mixed lubrication regime.

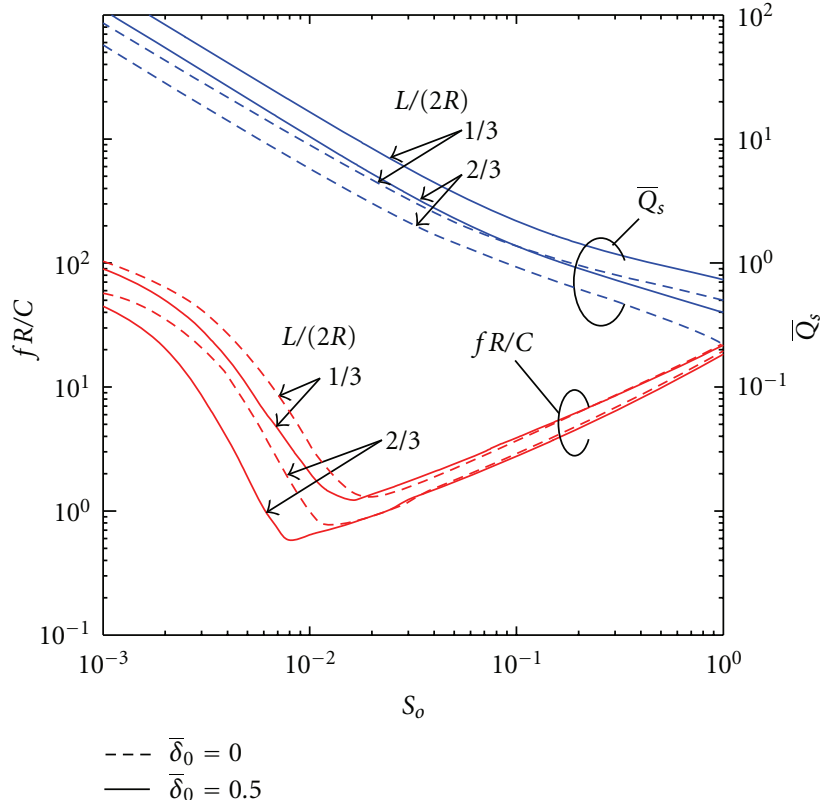

FIGURE 8: Effect of bearing-width ratio $L /(2 R)$ on frictional coefficient $f R / C$ and side leakage flow rate $\bar{Q}_{s}$ in terms of Sommerfeld number $S_{o}$ (no dent and $\bar{\delta}_{o}=0.5$ ).

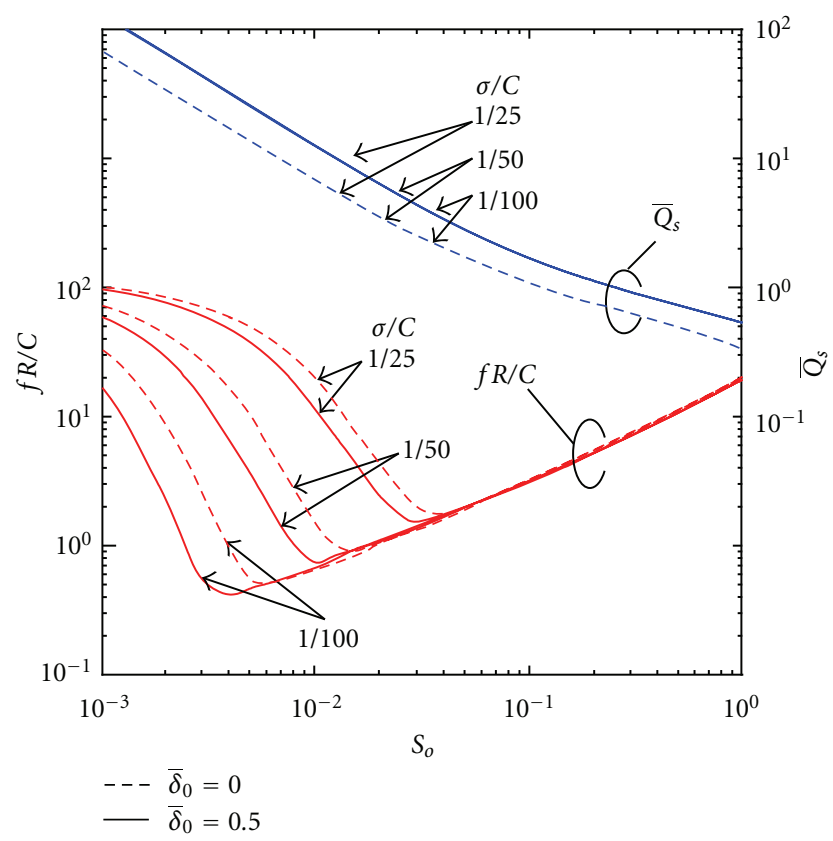

Figure 9: Effect of surface roughness $\sigma / C$ on frictional coefficient $f R / C$ and side leakage flow rate $\bar{Q}_{s}$ in terms of Sommerfeld number $S_{o}\left(\right.$ no dent and $\left.\bar{\delta}_{o}=0.5\right)$.

Figure 9 shows the effects of the surface roughness $\sigma / C$ on the friction coefficient $f R / C$ and the side leakage $\bar{Q}_{s}$ in terms of the Sommerfeld number $S_{o}$. $S_{o}$ for the transition from fluid film to mixed lubrication is larger for worn bearings. In contrast, the effect of $\sigma / C$ on the leakage $\bar{Q}_{s}$ is relatively low. 


\section{Conclusions}

The tribological characteristics of plain journal bearings with wear dents in mixed and fluid film lubrication are examined numerically under the steady-state condition. The effects of both the wear dent depth and the surface roughness interaction on the journal center loci, asperity pressure distributions, fluid pressure distributions, friction coefficient, and leakage flow rate are discussed in a wide range of operating conditions. The salient conclusions are as follows.

In mixed lubrication, for bearings with no dents, pressure peaks of the asperity-contact and fluid pressures are sharp; as the dent slightly increases, the peaks become small, and as the dent increases further, both the pressures increase. The friction coefficient is largest for bearings with no dents and smallest for those with shallow dents; for bearings with dents, this coefficient increases with the dent depth. In fluid film lubrication, the fluid pressure distribution shows two peaks or a peak and a hump for large dents. In addition, the friction coefficient is less influenced by the dent, and the leakage increases with the dent depth.

Similar tendencies are observed for smaller width bearings and rough surface bearings. A bearing with a slightly worn bush could reduce the maxima of the fluid and asperity-contact pressures.

\section{Nomenclature and Nondimensional Parameters}

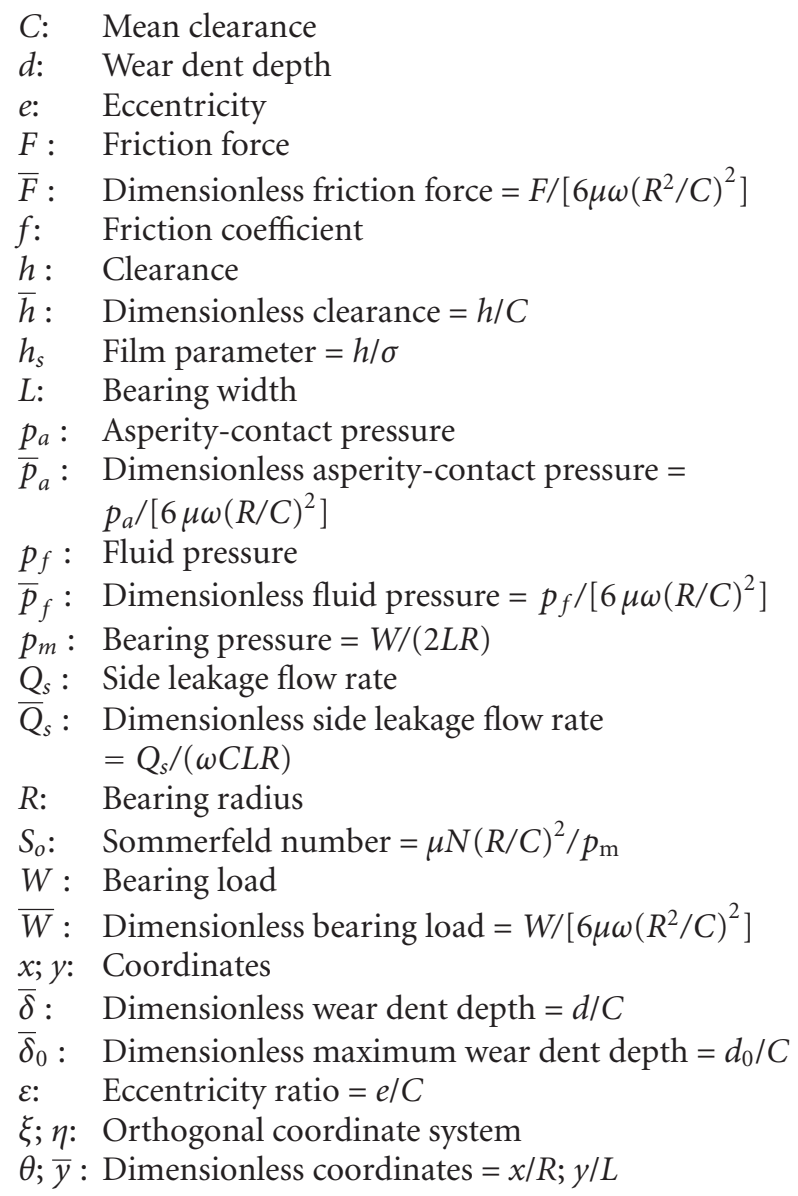

$\theta_{e}$ : Ending angle in contact

$\theta_{s}$ : Starting angle in contact

$\mu$ : Viscosity

$\sigma$ : Standard deviation of surface roughness height

$\phi$ : Attitude angle

$\omega$ : Journal angular velocity.

\section{Subscripts \\ a: Asperity \\ e: Elastic \\ $f$ : Fluid \\ p: Plastic \\ 0 : Reference.}

\section{Acknowledgment}

The authors would like to express their appreciation to Professor Emeritus Mitsuru Fujiwara of Muroran Institute of Technology.

\section{References}

[1] J. A. Williams, Engineering Tribology, Oxford Science Publications, Oxford, UK, 1994.

[2] B. J. Hamrock, Fundamentals of Fluid Film Lubrication. International Editions, McGraw-Hill, New York, NY, USA, 1994.

[3] Japanese Society of Tribologists, Ed., Tribology Handbook, Yokendo, Rokyo, Japan, 2001.

[4] G. E. Totten, Handbook of Lubrication and Tribology: Application and Maintenance, vol. 1, CRC Press, New York, NY, USA, 2nd edition, 2006.

[5] K. F. Dufrane, J. W. Kannel, and T. H. McCloskey, "Wear of steam turbine journal bBearings at low operating speeds," Journal of lubrication technology, vol. 105, no. 3, pp. 313-317, 1983.

[6] H. Hashimoto, S. Wada, and K. Nojima, "Performance characteristics of worn journal bearings in both laminar and turbulent regime, part 1: steady-state characteristics," ASLE transactions, vol. 29, no. 4, pp. 565-571, 1986.

[7] H. Hashimoto, S. Wada, and K. Nojima, "Performance characteristics of worn journal bearings in both laminar and turbulent regime, part 2: dynamic characteristics," ASLE transactions, vol. 29, no. 4, pp. 572-577, 1986.

[8] A. Kumar and S. S. Mishra, "Stability of a rigid rotor in turbulent hydrodynamic worn journal bearings," Wear, vol. 193, no. 1, pp. 25-30, 1996.

[9] A. Kumar and S. S. Mishra, "Steady state analysis of noncircular worn journal bearings in nonlaminar lubrication regimes," Tribology International, vol. 29, no. 6, pp. 493-498, 1996.

[10] M. Tanaka and K. Suzuki, "The stability characteristics of two-lobe journal bearings with surface wear dents (1st report, theoretical analysis)," Transactions of the Japan Society of Mechanical Engineers, vol. 68, no. 5, pp. 1441-1446, 2002.

[11] K. Suzuki and M. Tanaka, "The stability characteristics of twolobe journal bearings with surface wear dents (2nd report, experimental verification and nonlinear vibration analysis)," 
Transactions of the Japan Society of Mechanical Engineers, vol. 68, no. 5, pp. 1447-1452, 2002.

[12] M. Fillon and J. Bouyer, "Thermohydrodynamic analysis of a worn plain journal bearing," Tribology International, vol. 37, no. 2, pp. 129-136, 2004.

[13] S. A. McKee and T. R. McKee, "Journal-bearing friction in the region of thin-film ILubrication," SAE Journal, vol. 31, no. 3, pp. 371-377, 1932.

[14] J. T. Burwell, J. Kaye, D. W. van Nymegen, and D. A. Morgan, "Effects of surface finish," Transactions of the American Society of Mechanical Engineers, vol. 8, no. 2, pp. A-49-A-59, 1941.

[15] L. F. Kreisle, "Predominant-peak surface roughness, A criterion for minimum hydrodynamic oil-film thickness of short journal bearings," Transactions of the American Society of Mechanical Engineers, pp. 1235-1241, 1957.

[16] T. Kazama and M. Fujiwara, "Numerical analysis of multi-lobe hydrodynamic journal bearings in mixed lubrication," Journal of JSDE, vol. 39, no. 1, pp. 40-45, 2004.

[17] M. Nonogaki and T. Nakahara, "Approximate formula for the contact between truncated surfaces and frictional characteristics of a journal bearing in mixed lubrication," TriboTest, vol. 10, no. 3, pp. 225-240, 2004.

[18] Q. Wang and H. S. Cheng, "Mixed lubrication model for journal bearings with a thin soft coating-part I: contact and lubrication analysis," Tribology Transactions, vol. 38, no. 3, pp. 654-662, 1995.

[19] Q. J. Wang, F. Shi, and S. C. Lee, "A mixed-lubrication study of journal bearing conformal contacts," Journal of Tribology, vol. 119, no. 3, pp. 456-461, 1997.

[20] Y. Wang, C. Zhang, Q. J. Wang, and C. Lin, "A mixed-TEHD analysis and experiment of journal bearings under severe operating conditions," Tribology International, vol. 35, no. 6, pp. 395-407, 2002.

[21] N. Patir and H. S. Cheng, "Effect of surface roughness orientation on the central film thickness in E.H.D. contacts," in Elastohydrodynamics and Related Topics (proceedings of the 5th Leeds-Lyon Symposium on Tribology), pp. 15-21, Elsevier, 1979.

[22] J. A. Greenwood and J. B. P. Williamson, "Contact of nominally flat surfaces," Proceedings of Royal Society, London A, vol. 295, pp. 300-319, 1966.

[23] N. Patir and H. S. Cheng, "An average flow model for determining effects of three-dimensional roughness on partial hydrodynamic lubrication," Journal of Lubrication Technology, Transactions of the American Society of Mechanical Engineers, vol. 100, no. 1, pp. 12-17, 1978.

[24] N. Patir and H. S. Cheng, "Application of average flow model to lubrication between rRough sliding surfaces," Journal of Lubrication Technology, vol. 101, no. 2, pp. 220-230, 1979.

[25] A. Yamaguchi and H. Matsuoka, "Mixed lubrication model applicable to bearing/seal parts of hydraulic equipment," Journal of Tribology, vol. 114, no. 1, pp. 116-121, 1992.

[26] T. Kazama and A. Yamaguchi, "Application of a mixed lubrication model for hydrostatic thrust bearings of hydraulic equipment," Journal of Tribology, vol. 115, no. 4, pp. 686-691, 1993.

[27] K. L. Johnson, J. A. Greenwood, and S. Y. Poon, "A simple theory of asperity contact in elastohydro-dynamic lubrication," Wear, vol. 19, no. 1, pp. 91-108, 1972. 

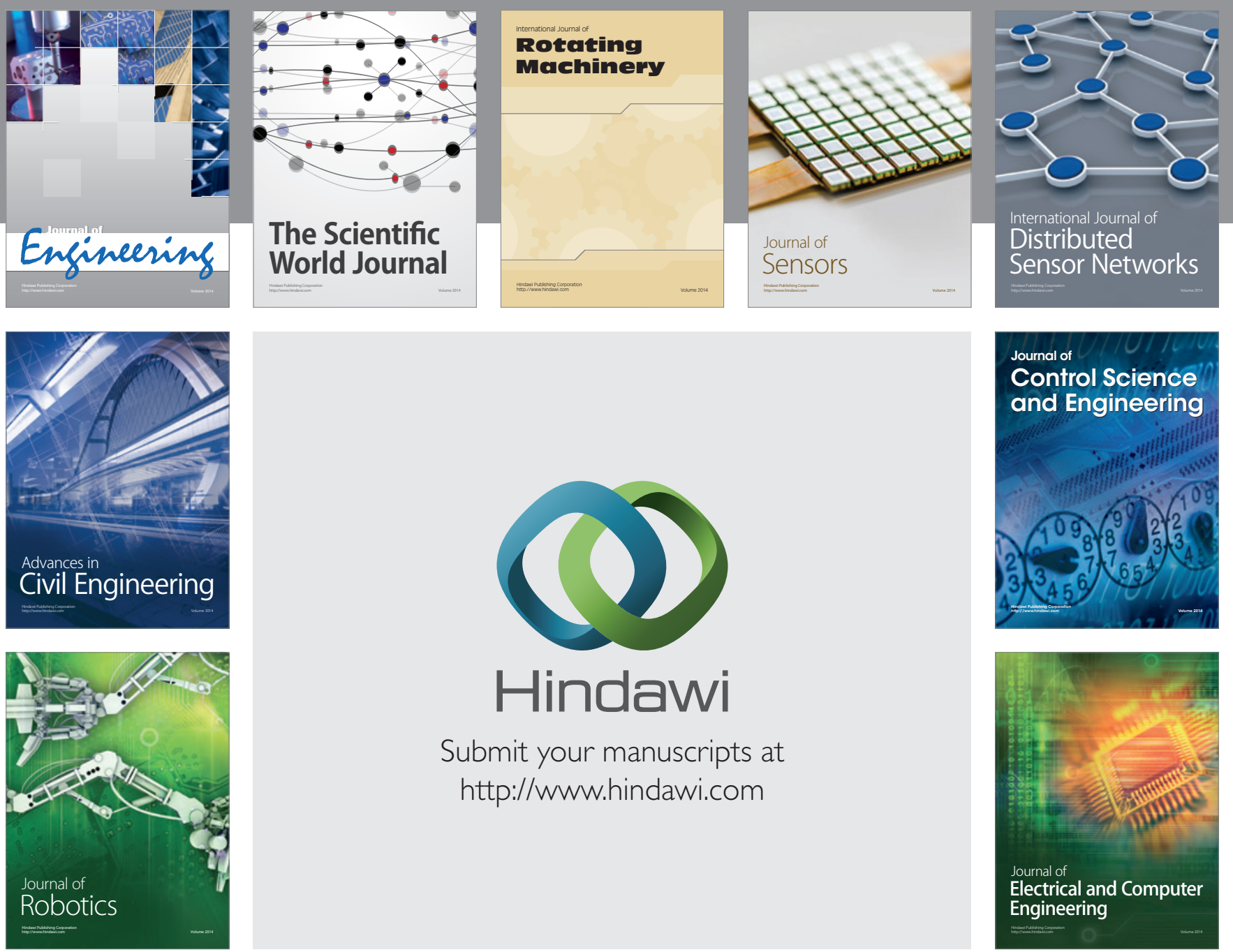

Submit your manuscripts at

http://www.hindawi.com
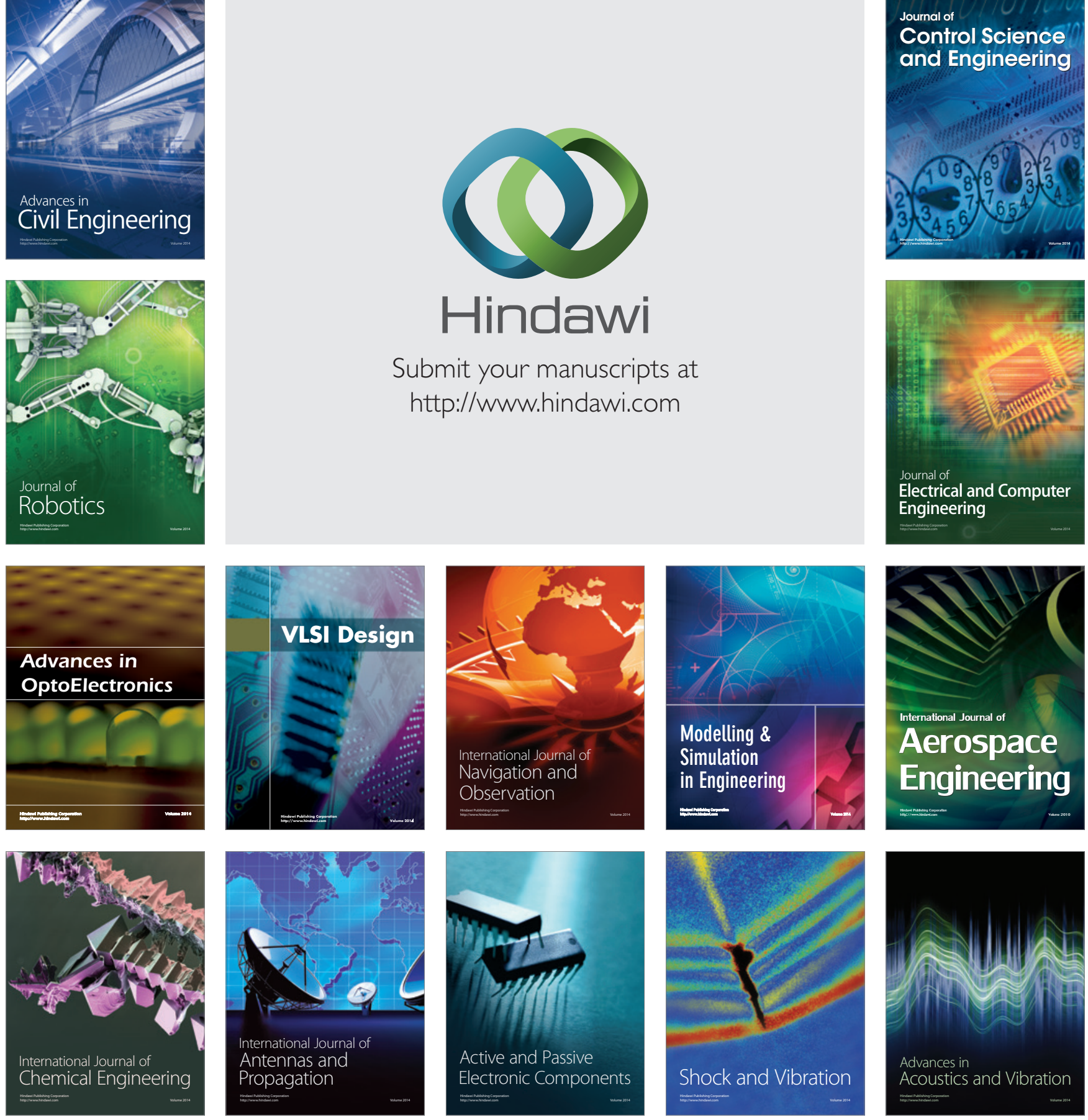